\title{
'Direct PCR' optimization yields a rapid, cost-effective, nondestructive and efficient method for obtaining DNA barcodes without DNA extraction
}

\author{
WING HING WONG, ${ }^{*}$ YWEE CHIEH TAY,$*$ JAYANTHI PUNIAMOORTHY,$*$ MICHAEL BALKE,† \\ PETER S. CRANSTON§ and RUDOLF MEIER*I \\ *Department of Biological Sciences, National University of Singapore, 14 Science Drive 4, Singapore 117543, Singapore, \\ $\uparrow$ GeoBioCenter, Ludwig-Maximilians-University, Richard-Wagner-Str. 10, 80333 Munich, Germany, $\$$ Zoological State Collection, \\ Münchhausenstr 21, D-81247 Munich, Germany, §Evolution, Ecology and Genetics, Research School of Biology, The Australian \\ National University, Canberra, ACT 0200, Australia, IIUniversity Scholars Programme, National University of Singapore, 14 \\ Science Drive 4, Singapore 117543, Singapore
}

\begin{abstract}
Macroinvertebrates that are collected in large numbers pose major problems in basic and applied biodiversity research: identification to species via morphology is often difficult, slow and/or expensive. DNA barcodes are an attractive alternative or complementary source of information. Unfortunately, obtaining DNA barcodes from specimens requires many steps and thus time and money. Here, we promote a short cut to DNA barcoding, that is, a nondestructive PCR method that skips DNA extraction ('direct PCR') and that can be used for a broad range of invertebrate taxa. We demonstrate how direct PCR can be optimized for the larvae and adults of nonbiting midges (Diptera: Chironomidae), a typical invertebrate group that is abundant, contains important bioindicator species, but is difficult to identify based on morphological features. After optimization, direct PCR yields high PCR success rates $(>90 \%)$, preserves delicate morphological features (e.g. details of genitalia, and larval head capsules) while allowing for the recovery of genomic DNA. We also document that direct PCR can be successfully optimized for a wide range of other invertebrate taxa that need routine barcoding (flies: Culicidae, Drosophilidae, Dolichopodidae, Sepsidae; sea stars: Oreasteridae). Key for obtaining high PCR success rates is optimizing (i) tissue quantity, (ii) body part, (iii) primer pair and (iv) type of Taq polymerase. Unfortunately, not all invertebrates appear suitable because direct PCR has low success rates for other taxa that were tested (e.g. Coleoptera: Dytiscidae, Copepoda, Hymenoptera: Formicidae and Odonata). It appears that the technique is less successful for heavily sclerotized insects and/or those with many exocrine glands.
\end{abstract}

Keywords: Chironomidae, DNA barcodes, DNA extraction, macroinvertebrates

Received 7 February 2014; revision received 5 May 2014; accepted 5 May 2014

'Any study in community ecology requires, ideally, that the individuals in a sample be properly counted and identified to species' Gotelli 2004

\section{Introduction}

DNA barcoding based on COI (5' cytochrome $c$ oxidase subunit 1) has been promoted as a method for species identification for many taxa (Hebert et al. 2003; Vences et al. 2005; Ward 2009; Dincă et al. 2011; Zou et al. 2011; Keskin \& Atar 2013). Arguably, DNA barcodes are particularly useful when morphological identification is

Correspondence: Rudolf Meier, Fax: +65-67792486, E-mail: meier@nus.edu.sg difficult, time-consuming and/or error-prone (Meier et al. 2008; Valentini et al. 2009; Schlick-Steiner et al. 2010). This is often the case for invertebrate taxa that are small and very abundant. Such hyperabundant yet hardto-identify taxa are the main obstacle to species-based bioassessment, biodiversity monitoring and community ecology. For these taxa, DNA barcoding can provide an alternative or complementary method to morphological identification (Pfenninger et al. 2007). However, this requires that the barcodes accurately reflect species boundaries for at least most species in a sample and that the sequences can be obtained rapidly and at low cost. We here address the latter two issues by promoting the use of 'direct PCR', a method that makes it cheaper and faster to obtain DNA barcodes. 
In direct PCR, the time and cost for obtaining DNA barcodes are reduced by placing tissue directly into a PCR master mix without DNA extraction prior to amplification of the target gene. This aids in reducing the time taken (4-16 h depending on extraction protocol) and cost by eliminating the usage of kits and decreasing manpower needs. Direct PCR procedures were proposed as early as 1993 (Panaccio et al. 1993), but success rates were either unreported or low. For example, Panaccio et al. (1993) and Grevelding et al. (1996) did not mention amplification success rates nor did they discuss whether the amplified specimens were suitable for morphological study and vouchering. Rochlin et al. (2007) evaluated the method by placing one Culex mosquito leg into the well containing PCR reagents and distilled water but reported low success rate $(<50 \%)$ that were not likely to encourage the use of this method. Yet, our experience with the method indicates that it can yield consistently high success rates $(>80 \%)$ for a wide range of taxa including flies (Culicidae, Drosophilidae, Dolichopodidae, Sepsidae) and sea stars (Oreasteridae). Key to success is the optimization of a few parameters. We thus consider direct PCR a convenient method for taxonomists and molecular ecologists who routinely have to obtain DNA barcodes for taxa, which are used widely for bioassessment or studies of genetic variability (e.g. Chironomidae, Culicidae, Drosophilidae).

\section{Direct PCR of Chironomidae}

We here use nonbiting midges (Diptera: Chironomidae) to describe how to optimize direct PCR. These midges are extremely abundant in many freshwater samples and routinely used as key bioindicator taxa for water quality assessment (Ferrington 2008; Luoto 2011; Milošević et al. 2013) as different species have distinct ecological preferences (Punti et al. 2009; Krosch \& Cranston 2012; Molozzi et al. 2012). However, accurate identification of chironomid larvae is difficult because the morphological features are often minuscule and easily obscured (Epler 2001; Sharley et al. 2004; Hajibabaei et al. 2011; Kim et al. 2012). These factors can lead to high error rates when the larvae are identified by parataxonomists (Cranston \& Hillman 1992; Krell 2004), thus impacting subsequent water quality analyses. In addition to identification problems, the cost of morphological identification is high because microscopic slides have to be prepared (Cranston 1994; Epler 2001; Carew et al. 2007; Cranston et al. 2013), which requires approximately 15-20 min per specimen. Yet, it is not unusual to find thousands of chironomid larvae in one environmental sample. It is therefore not surprising that the high cost of morphological identification has led to a debate whether chironomid larvae should be included in bioassessment of aquatic environments
(Kerans \& Karr 1994; Cranston 2000; Rabeni \& Wang 2001; Nijboer et al. 2005; Roque et al. 2010) although recent studies have shown that inclusion improves accuracy and signal-to-noise ratio (Ferrington 2008; Raunio et al. 2011; Brodin et al. 2013; Milošević et al. 2013). In addition, the high abundance of chironomids in urban aquatic systems can degrade the recreational value of waterfront areas. Thus, their mass occurrence can have serious economic implications and correct species-level identification for their control is crucial (Cranston et al. 2013).

Given the problems with morphology in this case, DNA barcodes are an obvious alternative or complementary tool as long as one can demonstrate that at least most midge species have discrete barcodes. Currently, the chironomid literature indicates that this is the case. Most barcoded species are separated by genetic distances of $>4 \%$ at the DNA barcode region while intraspecific variation rarely exceed 2\% (Ekrem et al. 2007, 2010; Sinclair \& Gresens 2008; Cranston et al. 2013). Beyond their use in routine identification, DNA barcodes have other important uses in Chironomidae. First, species are traditionally described based on adults, rendering larvae unidentifiable until they are associated with adults via rearing or DNA barcoding. Making such associations is important because larvae are the more important stage for freshwater assessment (Ferrington 2008; Marziali et al. 2009; Luoto 2011; Nandi et al. 2012 Milošević et al. 2013) and nowadays DNA barcodes are the choice method for this purpose (Carew et al. 2005; Ekrem et al. 2007). Second, DNA barcodes have been important for the discovery of putatively cryptic species (Ekrem et al. 2007; Sinclair \& Gresens 2008).

Here, we describe how an optimized direct PCR procedure without prior DNA extraction can yield success rates of $80-100 \%$ for a range of taxa. Furthermore, we document that direct PCR preserves the cuticle such that diagnostic morphological features can be studied and allows for the recovery of genomic DNA for the amplification of additional mitochondrial and nuclear genes. We also discuss other invertebrate taxa for which we were able to optimize direct PCR successfully.

\section{Materials and methods}

\section{Chironomidae}

Larvae and adults of various sizes and species were collected from three freshwater habitats (Bedok Reservior-1 ${ }^{\circ} 20^{\prime} 32^{\prime \prime} \mathrm{N} 103^{\circ} 55^{\prime} 30^{\prime \prime} \mathrm{E}$, Upper Seletar Reservior- $1^{\circ} 24^{\prime} 04^{\prime \prime} \mathrm{N} 103^{\circ} 48^{\prime} 14^{\prime \prime} \mathrm{E}$, Pandan Reservior- $1^{\circ} 18^{\prime} 50^{\prime \prime}$ N $103^{\circ} 44^{\prime} 30^{\prime \prime} \mathrm{E}$ ) in Singapore via sediment grab sampling (larvae) or light trapping (adults) and preserved in 70-100\% ethanol or isopropanol (Cranston et al. 2013). 
Larvae and adults were presorted into three size classes (Fig. 1). For adults, we consider 'small' midges to range from (anterior to posterior) 1.5-2.4 mm, 'medium' from 2.5 to $3.4 \mathrm{~mm}$ and 'large' $>3.5 \mathrm{~mm}$. The corresponding size classes for larvae are small $(3.0-4.4 \mathrm{~mm})$, medium (4.5-6.4 mm) and large (6.5-8.0).

\section{Direct PCR optimization}

We initially used whole specimens for direct PCR. The success rates with primer pair LCO 1490/HCO 2198 (Folmer et al. 1994) were as low as reported in the literature $(<50 \%$; Rochlin et al. 2007; small adults, $n=8,87.5 \%$ successful; medium adults, $n=4,0 \%$; large adults, $n=4,0 \%$; small larvae, $n=8,50 \%$; large larvae, $n=8,37.5 \%)$. Exceptions were the smallest adults $(1.5-2.4 \mathrm{~mm})$ that yielded high success rates. We thus adjusted the tissue amount for medium- and large-sized adults $(2.5-3.4 \mathrm{~mm}$ and $>3.5 \mathrm{~mm}$, respectively), and all three size classes of larvae (3.0$4.4 \mathrm{~mm}, \quad 4.5-6.4 \mathrm{~mm}$ and $6.5-8.0 \mathrm{~mm}$, respectively). High success rates were obtained when using (i) three legs from medium-sized adult and two legs from large-sized adults $(n=4: \quad 100 \%$ successful), (ii) the dissected anterior body segments from larvae of all three size classes (small larvae, $n=5: 80 \%$ successful; medium larvae, $n=10$ : $90 \%$ successful; large larvae, $n=5: 60 \%$ successful). We also experimented with another tissue source (dissected abdomen of mid- and large-sized adults; $n=4: 0 \%$ successful). After these trials with small numbers of specimens, we applied the methods to larger numbers of speci- mens (see below). In addition to tissue amount and source, the type of polymerase influenced PCR success rates. Four different polymerases were tested (TaKaRa ExTaq, Qiagen HotStar Taq, KAPA Taq and a homemade Taq). The total reaction volume was $20 \mu \mathrm{L}$, with $2 \mu \mathrm{L}$ of Taq $10 \times$ buffer, $1.5 \mu \mathrm{L}$ of $2 \mathrm{~mm}$ dNTPs, $1 \mu \mathrm{L}$ of $10 \mu \mathrm{M}$ primers and varying volume of Taq- and DNase-free sterile water depending on the Taq brand $(0.15 \mu \mathrm{L}$ TaKaRa ExTaq; $0.5 \mu \mathrm{L}$ Qiagen HotStar Taq; $0.5 \mu \mathrm{L}$ KAPA Taq; $1 \mu \mathrm{L}$ homemade Taq). The highest success rates were achieved using TaKaRa ExTaq while KAPA Taq and the homemade Taq gave successful amplifications, but the products were often 'smeary' under UV light. Qiagen HotStar Taq did not yield successful amplifications. Given that the removal of legs requires time, we tested also if whole specimens for midges and larvae in the mid- and large-sized classes could be used if a larger reaction volume $(40 \mu \mathrm{L})$ was used, but success rates were not as consistent and predictable as with $20 \mu \mathrm{L}$ and the tissues described above. Lastly, the addition of $1 \mu \mathrm{L}$ ( $1 \mathrm{mg} / \mathrm{mL}$ ) of bovine serum albumin (BSA) did not influence success rates.

\section{Optimized protocol for direct PCR and sequencing}

After optimizing direct PCR for chironomids, we tested the procedure with a new and larger batch of specimens (Table 2: 30-60). Whole specimens (small adults), three legs (medium adult), two legs (large adult), anterior half of larval body (small larvae), or head capsule and 2-3 anterior 'segments' (total length $=\sim 1 \mathrm{~mm}$ ) for the

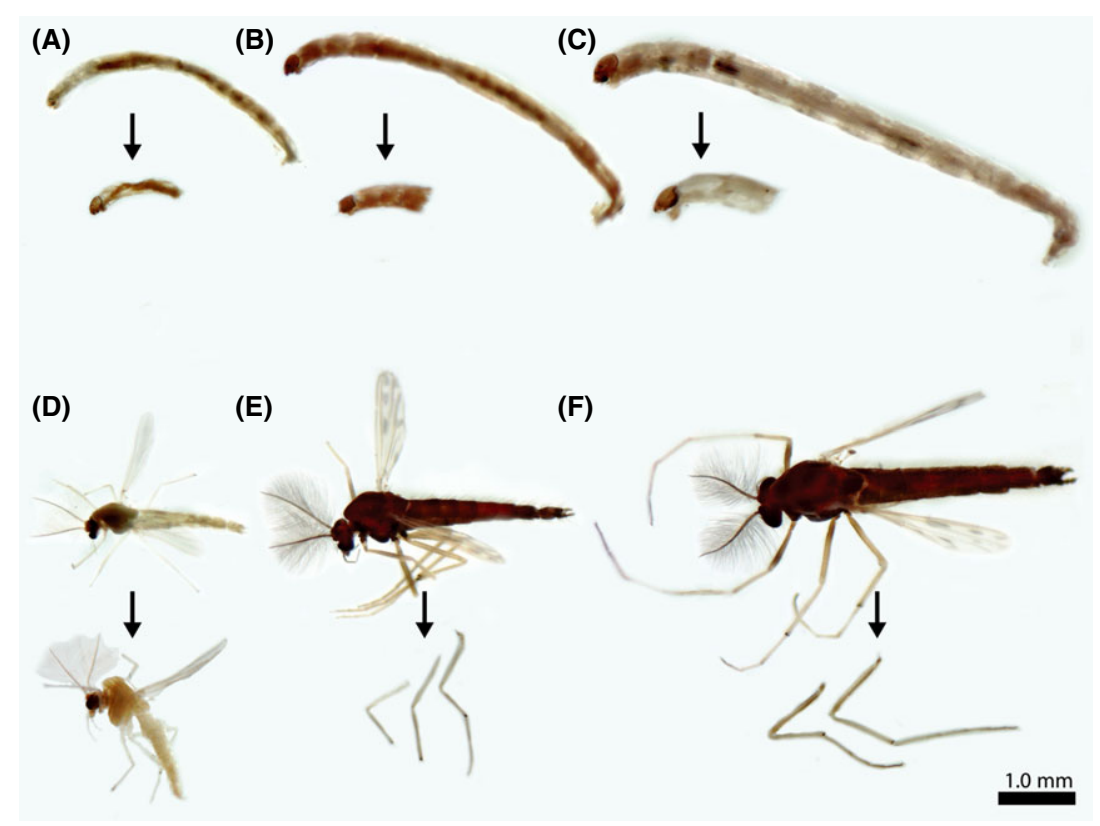

Fig. 1 Sizes of specimens and the corresponding parts (indicated by arrows) used for direct PCR. Larvae are shown in the top row: (A) small-sized larvae, (B) medium-sized larvae and (C) large-sized larvae. Adults are shown in the bottom row: (D) small-sized adults, (E) mediumsized adults and (F) large-sized adults. 
medium- and large-sized larvae were used. Relevant body parts intended for direct PCR were removed, dried briefly, then placed into the PCR wells and dried further for 1 min using a Speed-Vac. PCR reaction mixtures were prepared (20 $\mu \mathrm{L}$ volume: $2 \mu \mathrm{L}$ of $10 \times$ ExTaq Buffer, $1.5 \mu \mathrm{L}$ of $2 \mathrm{~mm}$ dNTP mixture, $0.15 \mu \mathrm{L}$ of TaKaRa ExTaq polymerase, $1 \mu \mathrm{L}$ of $10 \mu \mathrm{M}$ primers for the forward and reverse direction, DNase-free sterile water) and subsequently pipetted into the wells containing the dried specimens. The DNA barcoding region consisting of a 658-bp fragment of $\mathrm{COI}$ was amplified using the general invertebrate primers LCO 1490-5' GGT CAA CAA ATC ATA AAG ATA TTG G 3' and HCO 2198 5' TAA ACT TCA GGG TGA CCA AAA AAT CA 3' (Folmer et al. 1994). Cycling conditions were: denaturation at $94{ }^{\circ} \mathrm{C}$ for $30 \mathrm{~s}$, annealing at $51{ }^{\circ} \mathrm{C}$ for $30 \mathrm{~s}$ and extension at $72{ }^{\circ} \mathrm{C}$ for $1 \mathrm{~min}$. The cycle was repeated for 41 times. After PCR, the body parts inside the PCR wells were removed, preserved as vouchers in $70 \%$ or $100 \%$ ethanol and stored in $-20{ }^{\circ} \mathrm{C}$. The amplification results were checked with electrophoresis on a $1 \%$ agarose gel stained with GelRed (Biotium Inc.). Successfully amplified products were purified with SureClean ${ }^{\mathrm{TM}}$ (Bioline) according to the manufacturer's instructions. Purified products of smalland large-sized adults and larvae were sequenced in both directions with BigDye (PerkinElmer) terminator reactions and analysed on the ABI Avant 3130xl Genetic Analyzer. Medium-sized adults and larvae were sequenced in single direction (forward) after we found that single direction sequencing can yield $>500$ bases which is sufficient for routine species delimitation.

The chromatograms were assembled and edited using Sequencher ver. 4.6. Alignment of sequences was performed in MAFFT version 7 with default options. The alignments were translatable to amino acid sequences free of stop codons and the sequences checked via MEGABLAST in GenBank and compared to sequences in our own local database for chironomids of Pandan, Bedok, and Upper Seletar Reservoirs in Singapore (Cranston et al. 2013). The sequences were assigned to species clusters as described in Meier et al. (2006) using uncorrected pairwise distances $(4 \%)$ as recommended in Srivathsan \& Meier (2012).

\section{Retrieval of body parts for morphological study}

Adult chironomids are identified based on male genitalia, structures of the thorax and wing patterns, while larvae are distinguished based largely on characters of the head capsule (Cranston 1994; Epler 2001; Cranston et al. 2013). It was thus important to ascertain that specimens that had undergone direct PCR could still be used as vouchers. Slide mounts of specimens that had undergone direct PCR were prepared using Hoyer's mounting agent. For medium- and large-sized adult, this test was not needed because the diagnostically important body parts were not used during direct PCR and even the legs could be retrieved after direct PCR.

\section{Recovery of genomic DNA}

We tested two methods for recovering genomic DNA from the small adults that were exposed to direct PCR. First, the specimens from the PCR wells were taken out and subjected to DNA extraction using the DNeasy Blood and Tissue Kit (Qiagen) according to the manufacturer's protocol. For the second method, we performed genome amplification for 14 COI PCR products obtained with direct PCR earlier. The DNA was successfully amplified using the Repli-G Mini Kit (Qiagen) according to manufacturer's protocol but with halved reaction volumes (from 50 to $25 \mu \mathrm{L}$ ). Subsequently, PCRs were performed for three genes using the genomic DNA obtained by both methods (COI: nonbarcode segment; 18s: nuclear rDNA; AATS: segment 1, nuclear protein-encoding). These genes were used previously in phylogenetic studies of Chironomidae (Cranston et al. 2010, 2012; Dahle 2012; Krosch \& Cranston 2012). Primer sequences and PCR cycling conditions are provided in Table 1.

\section{Direct PCR of other taxa}

We subsequently used the same optimization procedures described here in an attempt to optimize direct PCR for other taxa (Copepoda; Coleoptera: Dytiscidae; Hymenoptera: Formicidae and Odonata; Diptera: Culicidae, Dolichopolidae, Drosophilidae and Sepsidae; Valvatida: Oreasteridae).

Specimens of Drosophilidae and Sepsidae were obtained from reared cultures at Temasek Life Sciences Laboratory and Evolutionary Biology Laboratory (National University of Singapore), respectively. Culicidae specimens were either obtained from Malaise traps or from cultures at Duke-NUS Graduate Medical School insectary, while all specimens of Dolichopolidae and Formicidae were collected from Malaise traps. The reared culture specimens were preserved in $100 \%$ ethanol, while the Malaise trap specimens were preserved in $70 \%$ ethanol. The Oreasteridae were sampled at Chek Jawa, Pulau Sekudu, Cyrene Reef, Pulau Semakau and Beting Bronok, while the Odonata samples came from Golf Link Marsh, Kent Ridge Park, Bishan Park, Nee Soon Swamp Forest and Pulau Ubin and the Copepoda samples from Pandan and Upper Seletar Reservoirs. The specimens were preserved in 100\% ethanol. All locations mentioned are in Singapore. The Dytiscidae specimens were collected in Brandenburg, Germany, and preserved in $96 \%$ ethanol. 
Table 1 Primers and cycling conditions used for PCRs of genome-amplified PCR products

\begin{tabular}{|c|c|c|c|}
\hline Locus/Primer & Primer sequence & Reference & Cycling condition \\
\hline \multicolumn{3}{|l|}{ COI } & \multirow{3}{*}{$\begin{array}{l}\text { Denaturation: } 94{ }^{\circ} \mathrm{C}, 30 \mathrm{~s} \\
\text { Annealing: } 51-54{ }^{\circ} \mathrm{C}, 30 \mathrm{~s} \\
\text { Extension: } 72{ }^{\circ} \mathrm{C}, 1 \mathrm{~min} 30 \mathrm{~s} \\
\text { Final extension: } 72{ }^{\circ} \mathrm{C}, 3 \mathrm{~min} \\
\text { Number of cycles: } 41\end{array}$} \\
\hline s2183 & 5' CAA CAT TTA TTT TGA TTT TTT GG 3' & Simon et al. (1994) & \\
\hline a3014 & $5^{\prime}$ TCC AAT GCA CTA ATC TGC CAT ATT A 3' & Simon et al. (1994) & \\
\hline \multicolumn{3}{|l|}{$18 \mathrm{~S}$} & \multirow{3}{*}{$\begin{array}{l}\text { Denaturation: } 94{ }^{\circ} \mathrm{C}, 1 \mathrm{~min} \\
\text { Annealing: } 55-58{ }^{\circ} \mathrm{C}, 1 \mathrm{~min} \\
\text { Extension: } 72{ }^{\circ} \mathrm{C}, 1 \mathrm{~min} 30 \mathrm{~s} \\
\text { Final extension: } 72{ }^{\circ} \mathrm{C}, 3 \mathrm{~min} \\
\text { Number of cycles: } 41\end{array}$} \\
\hline 18S_ai & 5' CCT GAG AAA CGG CTA CCA CAT C $3^{\prime}$ & Whiting et al. (1997) & \\
\hline 18S_bi & 5' GAG TCT CGT TCG TTA TCG GA 3' & Whiting et al. (1997) & \\
\hline \multicolumn{3}{|l|}{ AATS } & \multirow{3}{*}{$\begin{array}{l}\text { Denaturation: } 94{ }^{\circ} \mathrm{C}, 30 \mathrm{~s} \\
\text { Annealing: } 51-54{ }^{\circ} \mathrm{C}, 30 \mathrm{~s} \\
\text { Extension: } 72{ }^{\circ} \mathrm{C}, 1 \mathrm{~min} \\
\text { Final extension: } 72{ }^{\circ} \mathrm{C}, 3 \mathrm{~min} \\
\text { Number of cycles: } 41\end{array}$} \\
\hline A1-92F & 5' TAY CAY CAY CAN TTY TTY GAR ATG 3' & Regier (2008) & \\
\hline A1-244R & $5^{\prime}$ ATN CCR CAR TCN ATR TGY T 3' & Feng-Yi Su et al. (2008) & \\
\hline
\end{tabular}

\section{Results}

\section{Amplification success rate}

DNA barcodes were sequenced for three different size classes of chironomid adults and larvae. We tested $\geq 30$ specimens for each size class and stage. The direct PCR success rates were high, ranging from $90 \%$ to $100 \%$ for all size classes and stages (Table 2; see Fig. 2A). DNA sequence quality was comparable to what would have been obtained using traditional techniques involving DNA extraction (Fig. 2B). Sequence clustering at $4 \%$ using SpeciesIdentifier ver. 1.7.9 (Meier et al. 2006) revealed that the adult DNA barcodes belonged to eight molecular operational taxonomic units (MOTUs), while larval barcodes belonged to 10 MOTUs. According to our morphological and molecular databases for Singapore's reservoirs, the MOTUs belong to the following species/ genera: Tanytarsus oscillans Johannsen, 1932; Tanytarsus ovatus Johannsen, 1932; Cladotanytarsus sp.1, Cladotanytarsus sp. 2, Paratanytarsus sp.1, Polypedilum nubifer
Skuse, 1889; Polypedilum leei Freeman, 1961; Polypedilum (Pentapedilum) nodosum Johannsen, 1932; Polypedilum griseoguttatum Kieffer, 1921; Polypedilum sp. 1 and Chironomus circumdatus Kieffer, 1916.

For the nonchironomid taxa tested, the initial amplification success rates were low, but rose to $>80 \%$ for most taxa after optimizing tissue quantity, tissue type, primer pair and Taq polymerase (Table 3). Once optimized for a particular taxon, the same recipe worked consistently and could be used for subsequent samples. However, certain taxa appeared unsuitable for direct PCR. Regardless of body parts used (head, legs and thorax), Formicidae yielded low success rates of $<20 \%$, possibly due to glands that may produce PCR inhibitors (Billen 2009; Schrader et al. 2012). Optimization was also unsuccessful for the heavily sclerotized Dytiscidae and Copepoda. Of the taxa with less sclerotized legs/bodies, only Odonata failed to yield high success rates. The taxa that failed to amplify via direct PCR could be amplified with extracted DNA when using normal PCR recipes with the same primer pairs thus suggesting that direct PCR was the source of the problem.

Table 2 Chironomidae: number of direct PCR reactions and associated success rates. Refer to Dyrad doi in data accessibility for full specimen information

\begin{tabular}{lllcl}
\hline Morphospecies & Sample size & Successful attempts & Success rate for first amplification attempt (\%) & GenBank Accession no. \\
\hline Small adult & 62 & 59 & 95.2 & KJ530765-KJ530823 \\
Medium adult & 33 & 31 & 93.9 & KJ530824-KJ530854 \\
Large adult & 31 & 28 & 90.3 & KJ530855-KJ530882 \\
Small larvae & 30 & 30 & 100 & KJ530883-KJ530912 \\
Medium larvae & 30 & 29 & 96.7 & KJ530913-KJ530941 \\
Large larvae & 30 & 28 & 93.3 & KJ530942-KJ530969 \\
\hline
\end{tabular}


(A)

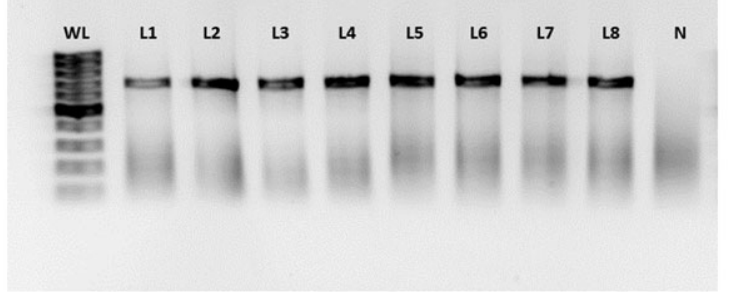

Fig. 2 (A) Agarose gel electrophoresis of direct PCR product from small-sized larvae 1 (L1-L8) using LCO-1490 and HCO-2198. WL, DNA weight ladder; N, negative control, (B) DNA sequence with BigDye nucleotide peaks visualized in DNA Sequencher (position 78 to position 224).

(B)

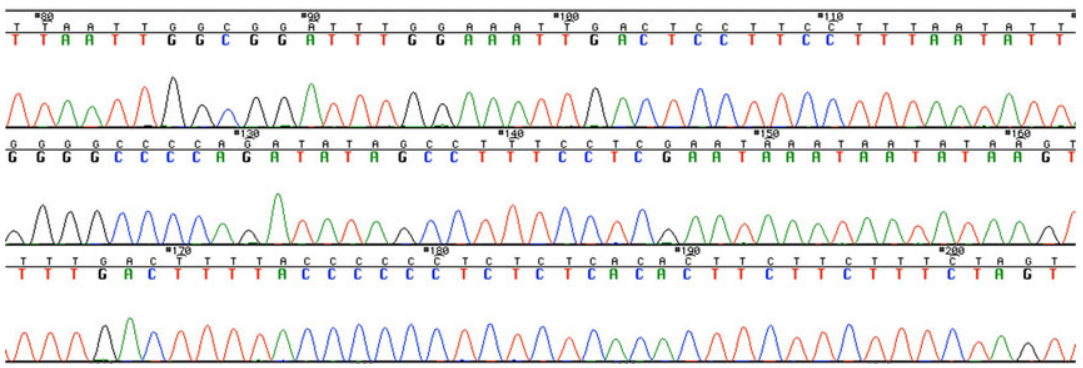

Recovery of morphological features and genomic DNA in Chironomidae

Direct PCR does not impair the morphologically important diagnostic characters. Male genitalia characters such as anal tergite bands, medium volsella, superior volsella, and gonostylus shapes, among others were preserved during direct PCR. Similarly, the characters of larvae such as the mentum, mandible, antenna etc were intact after the procedure (Fig. 3).

It is shown that genomic DNA can be recovered after direct PCR via one of the two methods tested. Of the two genomic DNA recovery methods described above, genome amplification of the direct PCR products proved more effective because the success rates for PCR of three nonbarcoding markers were significantly higher: COI: $100 \%(14 / 14)$, AATS1: $100 \%(14 / 14), 18 s$ rDNA: $78.6 \%(11 / 14)$ than those with extracted DNA: COI: 64.3\% (9/14), AATS1: 0\% (0/14), 18s rDNA: 21.4\% (3/14).

\section{Discussion}

Direct PCR has high success rates for a wide range of taxa once a few key parameters are optimized. The most critical factor is the amount of tissue because too little or too much template released during the initial heating step of PCR often leads to PCR failure, presumably due to a suboptimal reagent ratio (Kramer \& Coen 2001). Fortunately, nowadays PCR is successful across a fairly wide range of reagent ratios so that, for example, for chironomids we only have to differentiate between three different size classes in order to obtain high success rates. Note that high success rates for direct PCR are clade-independent because the tested specimens belong to five genera

Table 3 List of taxa and success rates for direct PCR

\begin{tabular}{|c|c|c|c|c|c|c|c|}
\hline Taxa & $\begin{array}{l}\text { Life } \\
\text { stages }\end{array}$ & $\begin{array}{l}\text { Body } \\
\text { parts used* }\end{array}$ & Primer Pairs (COI) & Sources & $\begin{array}{l}\text { Type of } \\
\text { polymerase }\end{array}$ & $\begin{array}{l}\text { Number of } \\
\text { successful } \\
\text { trials }\end{array}$ & $\begin{array}{l}\text { Success } \\
\text { rate }(\%)\end{array}$ \\
\hline Culicidae & Adult & $2-3$ legs & LEP F1/LEP R1 & Hebert et al. (2004) & $\begin{array}{c}\text { TaKaRa } \\
\text { ExTaq }\end{array}$ & $27 / 30$ & 90 \\
\hline Drosophilidae & Adult & $\begin{array}{l}\text { 2-3 legs/ } \\
\text { whole body }\end{array}$ & $\begin{array}{l}\text { LCO-1490/HCO-2198 } \\
\text { or LEP F1/LEP R1 }\end{array}$ & $\begin{array}{l}\text { Folmer et al. (1994)/ } \\
\text { Hebert et al. (2004) }\end{array}$ & $\begin{array}{l}\text { TaKaRa } \\
\text { ExTaq }\end{array}$ & $25 / 30$ & 83.3 \\
\hline Dolichopodidae & Adult & $1-3$ legs & LCO-1490/HCO-2198 & Folmer et al. (1994) & $\begin{array}{l}\text { homemade } \\
\text { Taq }\end{array}$ & $17 / 20$ & 85 \\
\hline Sepsidae & Adult & $1-3$ legs & $\mathrm{mtD} 4 / \mathrm{mtD} 9$ & Simon et al. (1994) & TaKaRa ExTaq & $77 / 95$ & 81.1 \\
\hline Oreasteridae & Adult & $1 \mathrm{~mm}^{3}$ tube foot & $\begin{array}{l}\text { tRNAasn42F/ } \\
\text { ValvaCOI-770R }\end{array}$ & Crandall et al. (2008) & homemade Taq & $78 / 83$ & 93.9 \\
\hline
\end{tabular}

*Depends on the size of specimens, c.f. Chironomidae's size. 

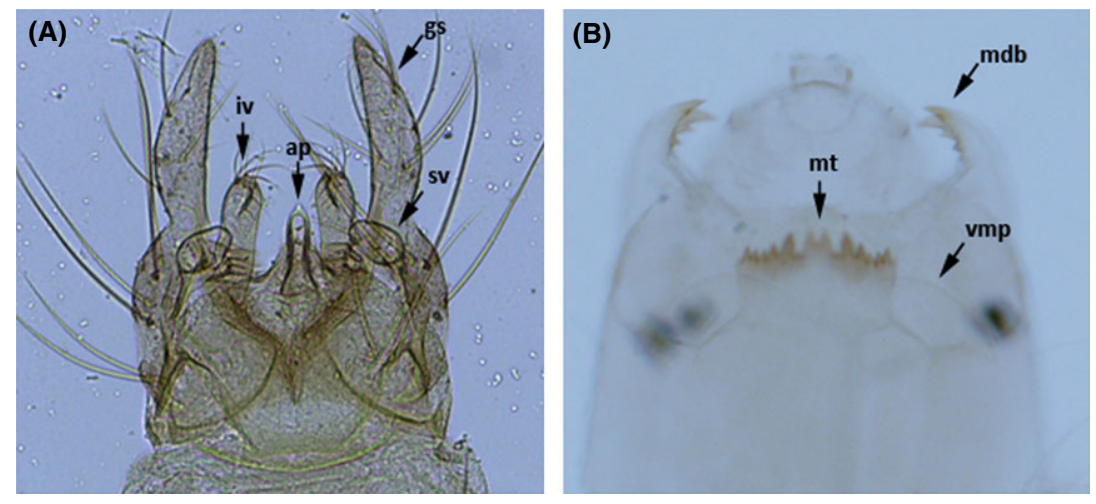

Fig. 3 Morphology of adults and larvae after direct PCR (A) Hypopygium morphology of Tanytarsus sp. ap, anal point; iv, inferior volsella; sv, superior volsella; gs, gonostylus. (B) Larval head capsule. $\mathrm{mt}$, mentum; vmp, ventromental plate; mdb, mandible.

(Tanytarsus, Cladotanytarsus, Paratanytarsus, Polypedilum, Chironomus). Adult chironomids like most other arthropods are particularly convenient tissue sources for direct PCR because (i) legs are easily removed thus providing a convenient way for scaling tissue quantity, (ii) they rarely contain large glands that may harbour PCR inhibitors, and (iii) they are bilaterally symmetrical so that diagnostic features can be retained on the specimen by removing only one leg on either side of the body. Should initial direct PCR fail, additional pairs of leg are available for a second trial. Note that the legs can be retrieved after the procedure without significant damages to the structures.

A second factor that influences direct PCR success rates is the choice of Taq polymerase. Over the years, we have observed that some taxa require expensive and high-fidelity Taq polymerases (e.g. Chironomidae) while high success rates can be attained for other taxa even with low-cost and homemade enzymes (e.g. Sepsidae). Given that simultaneous optimization of tissue quantity and enzyme is time-consuming, we recommend first optimizing the former with a high-fidelity Taq polymerase. Once PCR success rates are high, a cheaper and/or more versatile Taq polymerase can be tested. A third factor that influences PCR success rates is the source of tissues. For insects, legs generally work well while abdominal tissues should be avoided. Low success rates for the latter suggest that they may contain PCR inhibitors that could come from the digestive tract (Juen \& Traugott 2006). If abdominal tissues cannot be avoided (e.g. chironomid larvae), success rates increase when the anterior-most abdominal segments are used. In addition, we have recently increased success rates further using more specific primer pairs (LEP F1/LEP R1 instead of LCO 1490/HCO 2198 for insect taxa). Lastly, not surprisingly, storage conditions of specimens influence success rates. Fresh specimens that are used immediately after preservation and/or are stored at low temperatures amplify easily, whereas older material with inferior preservation and storage conditions can fail. There are excep- tions, however, and we routinely use direct PCR successfully for Malaise trap material preserved initially in $70 \%$ ethanol (Dolichopodidae).

\section{Direct PCR: why now?}

Given that direct PCR procedures have been known for more than 20 years, one has to wonder why they have not been widely adopted. We believe that there are three reasons. First, early publications on direct PCR reported low or no success rates which are unlikely to encourage the adoption of the method. We find that such discouragingly low rates are normal during initial rounds of direct PCR optimization. We believe that some laboratories have tried direct PCR, but abandoned it following low, initial success rates. These laboratories never went to the optimization stage.

Second, scientists may feel uneasy about direct PCR procedures that use whole specimens because the initial barcode may reveal that a specimen belongs to a particularly interesting species. Sequencing of additional genes is then desirable, but it remained untested whether genomic DNA can be recovered from a specimen that had already been used in direct PCR. We here show that this is possible as long as a genome amplification of the original amplification product is performed. Using the amplified genome as template, we were able to sequence additional mitochondrial and nuclear markers. Initially, we worried that such procedure would overamplify the $\mathrm{COI}$ sequence because it is already enriched in the direct PCR product, but the primers used by the Repli-G Mini Kit appear to be sufficiently diverse that genomic DNA is amplified effectively. Note that the recovery of template DNA via genome amplification is needed only for small specimens where the whole body is used as template in direct PCR. For most specimens, direct PCR utilizes only legs so that most of the specimen remains in pristine condition and can be used for DNA extraction.

Lastly, based on previous studies on direct PCR, it was unclear whether the morphology of specimens 
undergoing direct PCR remained intact for vouchering. In this study, we found that even sensitive and small body parts are well preserved. Re-identification and description of specimens that have undergone direct PCR can be performed.

\section{Direct PCR: still relevant?}

Molecular ecology and bioassessment are quickly adopting next-generation-sequencing (NGS) (Hajibabaei et al. 2011; Carew et al. 2013) and one may wonder whether there is still a need for a technique such as direct PCR. However, the analysis of NGS data generally involves the identification of species (e.g. food species) via barcode-like markers (Porazinska et al. 2009; Zhou et al. 2013). Hence, DNA barcode databases are still very much needed. Unfortunately, these databases remain extremely species-poor for many groups (Harris 2003; Ekrem et al. 2007; Begerow et al. 2010; Kwong et al. 2012; Kvist 2013). Improving species coverage will require a large amount of species-specific Sanger sequencing in order to obtain new DNA barcodes for additional species. Given that many very common species have already been barcoded, most new barcodes will have to be generated for rare species and these are likely to be produced by laboratories that specialize in particular taxa and that thus have an incentive for optimizing direct PCR for these taxa. Indeed, much of the species coverage for COI sequences in GenBank already comes from projects that are unlikely to be associated directly with DNA barcoding studies (Kwong et al. 2012).

Direct PCR will be particularly attractive for two types of laboratories. The first type is invertebrate systematics laboratories. Such laboratories routinely acquire large numbers of specimens in target groups. Many such laboratories have already adopted sample processing procedures that consist of rough sorting based on morphology with subsequent testing of the morphological units via $\mathrm{COI}$ sequencing for exemplars from the putative morpho-species (Tan et al. 2010). Species identification is ultimately achieved through the evaluation of multiple data sources (Tan et al. 2010; Yeates et al. 2011). This procedure requires that many specimens are barcoded and any shortcut to the process (e.g. direct PCR) is very welcome. The second type of laboratories that should be interested in direct PCR is those that employ parataxonomists in bioassessment. These laboratories are increasingly aware that the accuracy of the sorting by paratoxonomist can be improved through a feedback loop that provides information on the validity of the morphospecies that were delimited by parataxonomists (Stribling et al. 2008). Ideally, the verification source is taxonomic experts, but they are often not available and the next best choice would be DNA barcodes. Again, for these laboratories, a cheaper and faster technique for generating barcodes will help with implementing iterative procedures for validating parataxonomists' morphospecies boundaries. Moreover, the DNA barcodes generated can serve as libraries that are subsequently used for NGS-based bioassessment.

\section{Conclusions}

Direct PCR is an old technique neglected by most molecular ecologists. However, our study demonstrates that for many taxa, high success rates can be achieved without substantial damage to specimens once PCR conditions have been optimized. This reduces overall sequencing cost by saving time via skipping the DNA extraction step. Based on several years of experience, we only occasionally encounter taxa for which direct PCR optimization fails. Note that further reductions in cost can be achieved through one-directional sequencing, which is sufficient for routine identifications.

\section{Acknowledgements}

We would like to express our gratitude to Rayson Lim, Audrey Heyzer (Tropical Marine Science Institute) and Jeremy Woodford (Environmental Health Institute) for providing the chironomid specimens. We also wish to thank Dr. Ian Mendenhall and the insectary at Duke-NUS Graduate Medical School for providing the material for Culicidae. The images were prepared with the help of Ang Yuchen (Evolutionary Biology Laboratory, National University of Singapore). We also thank Diego Pitta de Araujo and Amrita Srivathsan (Evolutionary Biology Laboratory, National University of Singapore) for their input in the preparation of manuscript. Funding was provided by a grant from the Public Utility Board (Singapore), WBS: R-154-000-526-490.

\section{References}

Begerow D, Nilsson H, Unterseher M, Maier W (2010) Current state and perspectives of fungal DNA barcoding and rapid identification procedures. Applied Microbiology and Biotechnology, 87, 99-108.

Billen J (2009) Occurrence and structural organization of the exocrine glands in the legs of ants. Arthropod Structure E Development, 38, 2-15.

Brodin Y, Ejdung G, Strandberg J, Lyrholm T (2013) Improving environmental and biodiversity monitoring in the Baltic Sea using DNA barcoding of Chironomidae (Diptera). Molecular Ecology Resources, 13, 996-1004.

Carew ME, Pettigrove V, Hoffmann AA (2005) The utility of DNA markers in classical taxonomy: using cytochrome oxidase 1 markers to differentiate Australian Cladopelma (Diptera: Chironomidae) midges. Annals of the Entomological Society of America, 98, 587-594.

Carew ME, Pettigrove V, Cox RL, Hoffmann AA (2007) DNA identification of urban Tanytarsini chironomids (Diptera: Chironomidae). Journal of the North America Benthological Society, 26, 587-600.

Carew ME, Pettigrove V, Metzeling L, Hoffmann AA (2013) Environmental monitoring using next generation sequencing: rapid identification of macroinvertebrate bioindicator species. Frontiers in Zoology, 10, 45 . 
Crandall ED, Jones ME, Munoz MM, Akinronbi B, Erdmann MV, Barber $\mathrm{PH}$ (2008) Comparative phylogeography of two seastars and their ectosymbionts within the Coral Triangle. Molecular Ecology, 17, 5276-5290.

Cranston PS (1994) Systematics. In: The Chironomidae: Biology and Ecology of Non-biting Midges (eds Armitage PD, Cranston PS, Pinder LCV), pp. 31-61. Chapman and Hall, London, Glasgow, New York, Tokyo, Melbourne, Madras.

Cranston PS (2000) Monsoonal tropical Tanytarsus van der Wulp (Diptera: Chironomidae) reviewed: new species, life histories and significance as aquatic environmental indicators. Australian Journal of Entomology, 39, 138-159.

Cranston PS, Hillman P (1992) Rapid assessment of biodiversity using 'biological diversity technicians'. Australian Biologist, 5, 144-155.

Cranston PS, Hardy NB, Morse GE, Pusledink L, McCluen SR (2010) When molecules and morphology concur: the 'Gondwana' midges (Diptera: Chironomidae). Systematic Entomology, 35, 636-648.

Cranston PS, Hardy NB, Morse GE (2012) A dated molecular phylogeny for the Chironomidae (Diptera). Systematic Entomology, 37, 172-188.

Cranston PS, Ang YC, Heyzer A et al. (2013) The nuisance midges (Diptera: Chironomidae) of Singapore's Pandan and Bedok reservoirs. The Raffles Bulletin of Zoology, 61, 779-793.

Dahle S (2012) Phylogenetic analysis of the genus Paratanytarsus (Diptera: Chironomidae). Master's Thesis, Norwegian University of Science and Technology. Available from ntnu.diva-portal.org/smash/get/diva 2:608830/FULLTEXT01.pdf.

Dincă V, Zakharov EV, Hebert PDN, Vila R (2011) Complete DNA barcode reference library for a country's butterfly fauna reveals high performance for temperate Europe. Proceedings. Biological Sciences/The Royal Society, 278, 347-355.

Ekrem T, Willassen E, Stur E (2007) A comprehensive DNA sequence library is essential for identification with DNA barcodes. Molecular Phylogenetics and Evolution, 43, 530-542.

Ekrem T, Stur E, Hebert PDN (2010) Females do count: documenting Chironomidae (Diptera) species diversity using DNA barcoding. Organisms Diversity and Evolution, 10, 397-408.

Epler JH (2001) Identification manual for the larval Chironomidae (Diptera) of North and South Carolina. North Carolina Department of Environmental and Natural Resources; Division of Water Quality, Special publication SJ2001-SP13.

Feng-Yi Su K, Narayanan Kutty S, Meier R (2008) Morphology versus molecules: the phylogenetic relationships Sepsidae (Diptera: Cyclorrhapha) based on morphology and DNA sequence data from ten genes. Cladistics, 24, 902-916.

Ferrington LC (2008) Global diversity of non-biting midges (Chironomidae: Insecta-Diptera) in freshwater. Hydrobiologia, 595, 447-455.

Folmer O, Black M, Hoeh W, Lutz R, Wrijenhoek R (1994) DNA primers for amplification of mitochondrial cytochrome $\mathrm{c}$ oxidase subunit 1 from diverse metazoan invertebrates. Molecular Marine Biology and Biotechnology, 3, 294-299.

Freeman P (1961) The Chironomidae (Diptera) of Australia. British Musuem (Natural History), London, 731 pp.

Gotelli NJ (2004) A taxonomic wish-list for community ecology. Philosophical Transactions of the Royal Society of London. Series B, Biological Sciences, 359, 585-597.

Grevelding CG, Kampkötter A, Hollmann M, Schäfer U, Kunz W (1996) Direct PCR on fruitflies and blood flukes without prior DNA extraction. Nucleic Acids Research, 24, 4100-4101.

Hajibabaei M, Shokralla S, Zhou X, Singer GAC, Baird DJ (2011) Environmental barcoding: a next-generation sequencing approach for biomonitoring applications using river benthos. PLoS One, 6, e17497.

Harris DJ (2003) Can you bank on GenBank? Trends in Ecology and Evolution, 18, 317-319.

Hebert PDN, Cywinska A, Ball SL, deWaard JR (2003) Biological identifications through DNA barcodes. Proceedings of the Royal Society - Bio$\log y, 270,313-321$.

Hebert PDN, Stoeckle MY, Zemlak TS, Francis CM (2004) Ten species in one: DNA barcoding reveals cryptic species in the neotropical skipper butterfly Astraptes fulgerator. Proceedings of the National Academy of Sciences of the United States of America, 101, 14812-14817.

Johannsen OA (1932) Chironominae of the Malayan Subregion of the Dutch East Indies. Archiv fiir Hydrobiologie, Supplement, 11, 503-552.

Juen A, Traugott M (2006) Amplification facilitators and multiplex PCR: tools to overcome PCR-inhibition in DNA-gut-content analysis of soil living invertebrates. Soil Biology and Biochemistry, 38, 1872-1879.

Kerans B, Karr JR (1994) A benthic index of biotic integrity (B-IBI) for rivers of the Tennessee Valley. Ecological Application, 4, 768-785.

Keskin E, Atar HH (2013) DNA barcoding commercially important fish species of Turkey. Molecular Ecology Resources, 13, 788-797.

Kieffer JJ (1916) Tendipedides (Chironomides) de Formose conservés au Muséum National Hangrois de Budapest et détérmines par J. J. KIEFFER. Annales historic-naturales Musei nationalis Hungarici, 14, 81-121.

Kieffer JJ (1921) Nouveaux representants du genre Polypedilum (Chironomides). Annales de la Société Scientifiques Bruxelles, 41, 97-101.

Kim S, Song K, Ree H, Kim W (2012) A DNA barcode library for Korean Chironomidae (Insecta: Diptera) and indexes for defining barcode gap. Molecules and Cells, 33, 9-17.

Kramer MF \& Coen DM (2001) Enzymatic amplification of DNA by PCR: standard procedures and optimization. In: Current Protocols in Molecular Biology, Unit 15.1, October 2001 (ed. Harkins B) 15.1.1-15.1.14. John Wiley \& Sons Inc., Hoboken, New Jersey, 2003.

Krell FT (2004) Parataxonomy vs taxonomy in biodiversity studies - pitfalls and applicability of 'morphospecies' sorting. Biodiversity and Conservation, 13, 795-812.

Krosch MN, Cranston PS (2012) Non-destructive DNA extraction from Chironomidae, including of fragile pupal exuviae, extends analyzable collections and enhances vouchering. Chironomus Newsletter on Chironomidae Research, 25, 22-27.

Kvist S (2013) Barcoding in the dark?: a critical view of the sufficiency of zoological DNA barcoding databases and a plea for broader integration of taxonomic knowledge. Molecular Phylogenetics and Evolution, 69, 39-45.

Kwong S, Srivathsan A, Meier R (2012) An update on DNA barcoding: low species coverage and numerous unidentified sequences. Cladistics, 28, 639-644.

Luoto TP (2011) The relationship between water quality and chironomid distribution in Finland - a new assemblage-based tool for assessments of long term nutrient dynamics. Ecological Indicators, 11, 255-262.

Marziali L, Armanini DG, Cazzola M et al. (2009) Responses of Chironomid larvae (Insecta, Diptera) to ecological quality in Mediterranean river mesohabitats (South Italy). River Research and Applications, 26, 1036-1051.

Meier R, Kwong S, Vaidya G, Ng PKL (2006) DNA barcoding and taxonomy in Diptera: a tale of high intraspecific variability and low identification success. Systematic Biology, 55, 715-728.

Meier R, Zhang GY, Ali F (2008) The use of mean instead of smallest interspecific distances exaggerates the size of "Barcoding Gap" and leads to misidentification. Systematic Biology, 57, 809-813.

Milošević D, Simić V, Stojković M et al. (2013) Spatio-temporal pattern of the Chironomidae community: toward the use of non-biting midges in bioassessment programs. Aquatic Ecology, 47, 37-55.

Molozzi J, Feio MJ, Salas F, Marques JC, Callisto M (2012) Development and test of a statistical model for the ecological assessment of tropical reservoirs based on benthic macroinvertebrates. Ecological Indicators, 23, 155-156.

Nandi S, Aditya G, Saha GK (2012) Nutrient conditions and chironomid productivity in Kolkata, India: assessment for biomonitoring and ecological management. Journal of Limnology, 71, 320-329.

Nijboer RC, Verdonschot PFM, Van Der Werf DC (2005) The use of indicator taxa as representatives of communities in bioassessment. Freshwater Biology, 50, 1427-1440.

Panaccio M, Georgesz M, Hollywell C, Lew A (1993) Direct PCR from solid tissue without DNA extraction. Nucleic Acids Research, 21, 4656.

Pfenninger M, Nowak C, Kley C, Steinke D, Streit B (2007) Utility of DNA taxonomy and barcoding for the inference of larval community 
structure in morphologically cryptic Chironomus (Diptera) species. Molecular Ecology, 16, 1957-1968.

Porazinska DL, Giblin-Davis RM, Faller L et al. (2009) Evaluating highthroughput sequencing as a method for metagenomic analysis of nematode diversity. Molecular Ecology Resources, 9, 1439-1450.

Punti T, Rieradevall M, Prat N (2009) Environmental factors, spatial variation, and specific requirements of Chironomidae in Mediterranean reference streams. Journal of the North America Benthological Society, 28, 247-265.

Rabeni CF, Wang N (2001) Bioassessment of streams using macroinvertebrates: are the Chironomidae necessary? Environmental Monitoring and Assessment, 71, 177-185.

Raunio J, Heino J, Paasivirta L (2011) Non-biting midges in biodiversity conservation and environmental assessment: findings from boreal freshwater ecosystems. Ecological Indicators, 11, 1057-1064.

Regier JC (2008) Protocols, concepts, and reagents for preparing DNA sequencing templates. Version 12/4/08. Available from www.umbi. umd.edu/users/jclab/PCR_primers.pdf.

Rochlin I, Santoriello MP, Mayer RT, Campbell SR (2007) Improved high-throughput method for molecular identification of Culex mosquitoes. Journal of the American Mosquito Control Association, 23, 488-491.

Roque FO, Siqueira T, Bini LM et al. (2010) Untangling associations between chironomid taxa in Neotropical streams using local and landscape filters. Freshwater Biology, 55, 847-865.

Schlick-Steiner BC, Steiner FM, Seifert B, Stauffer C, Christian E, Crozier RH (2010) Integrative taxonomy: a multisource approach to exploring biodiversity. Annual Review of Entomology, 55, 421-428.

Schrader C, Schielke A, Ellerbroek L, Johne R (2012) PCR inhibitors occurrence, properties and removal. Journal of Applied Microbiology, 113, 1014-1026.

Sharley DJ, Pettigrew V, Parsons YV (2004) Molecular identification of Chironomus spp. (Diptera) for biomonitoring of aquatic ecosystems. Australian Journal of Entomology, 43, 359-365.

Simon C, Frati F, Beckenbach A, Crespi B, Liu H, Flook P (1994) Evolution weighing, and phylogenetic utility of mitochondrial gene sequences and a compilation of conserved polymerase chain reaction primers. Annals of the Entomological Society of America, 87, 651-701.

Sinclair CS, Gresens SE (2008) Discrimination of Cricotopus species (Diptera: Chironomidae) by DNA barcoding. Bulletin of Entomological Research, 98, 555-563.

Skuse FAA (1889) Diptera of Australia. Part VI. The Chironomidae. Proceedings of the Linnean Society of New South Wales, 2, 215-311.

Srivathsan A, Meier R (2012) On the inappropriate use of Kimura-2parameter (K2P) divergences in the DNA barcoding literature. Cladistics, 28, 190-194.

Stribling JB, Pavlik KL, Holdsworth SM, Leppo EW (2008) Data quality, performance, and uncertainty in taxonomic identification for biological assessments. Journal of the North American Benthological Society, 27, 906-919.
Tan DSH, Ang Y, Lim GS, Ismail MR, Meier R (2010) From 'cryptic species' to integrative taxonomy: an iterative process involving DNA sequences, morphology, and behaviour leads to the resurrection of Sepsis pyrrhosoma (Sepsidae: Diptera). Zoologica Scripta, 39, 51-61.

Valentini A, Pompanon F, Taberlet P (2009) DNA barcoding for ecologists. Trends in Ecology and Evolution, 24, 110-117.

Vences M, Thomas M, Bonett RM, Vieites DR (2005) Deciphering amphibian diversity through DNA barcoding: changes and challenges. Philosophical Transactions of the Royal Society of London. Series B, Biological Sciences, 360, 1859-1868.

Ward RD (2009) DNA barcode divergence among species and genera of birds and fishes. Molecular Ecology Resources, 9, 1077-1085.

Whiting MF, Carpenter JC, Wheeler QD, Wheeler WC (1997) The Strepsiptera problem: phylogeny of the holometabolous insect orders inferred from $18 \mathrm{~S}$ and $28 \mathrm{~S}$ ribosomal DNA sequences and morphology. Systematic Biology, 46, 1-68.

Yeates DK, Seago A, Nelson L, Cameron SL, Joseph L, Trueman JWH (2011) Integrative taxonomy, or iterative taxonomy? Systematic Entomology, 36, 209-217.

Zhou X, Li Y, Liu S et al. (2013) Ultra-deep sequencing enables high-fidelity recovery of biodiversity for bulk arthropod samples without PCR amplification. GigaScience, 2, 4 .

Zou S, Li Q, Kong L, Yu H, Zheng X (2011) Comparing the usefulness of distance, monophyly and character-based DNA barcoding methods in species identification: a case study of Neogastropoda. PLoS One, 6, e26619.

W.H.W. and R.M. conceived the study and designed the experimental setups with input from M.B. and P.S.C. Y.C.T. and J.P. performed direct PCR optimization on Oreasteridae and Dolichopodidae respectively, while optimization of other nonchironomid taxa was performed by W.H.W. Analysis of data and writing of manuscript were done by W.H.W., with input from R.M., M.B. and P.S.C.

\section{Data Accessibility}

DNA sequences are uploaded to NCBI and have the following GenBank accession nos KJ530765-KJ530969. Sequence alignment and an Excel file containing individual specimen information were deposited in the Dryad database (doi: 10.5061/dryad.4q4kf). 